\title{
An Evaluation of Monitoring Surveys of the Quarantine Bacterium Xylella Fastidiosa Performed in Containment and Buffer Areas of Apulia, Southern Italy
}

Applied Biosafety:

Journal of ABSA International 2019, Vol. 24(2) 96-99

(C) ABSA International 2019

Article reuse guidelines:

sagepub.com/journals-permissions DOI: $10.1177 / 1535676019845738$ journals.sagepub.com/home/apb

(S)SAGE

\author{
Marco Scortichini' and Gianluigi Cesari ${ }^{2}$
}

\begin{abstract}
Introduction: Xylella fastidiosa is a quarantine phytopathogen for the European Plant Protection Organization and currently infects olive trees in the Apulia region (southern Italy). Upon the Implementing Decision of the European Union 2016/764 of May 12,2016 , extensive monitoring surveys were performed on approximately 190000 ha to ascertain the possible occurrence of $X$. fastidiosa.

Objectives: The primary objectives of the analysis were to start to collect epidemiological data on $X$. fastidiosa occurrence in areas far from the initial outbreaks and discuss the results of the pathogen detection.

Methods: A total of 220279 olive trees were inspected. Basic information on farm and trees management was obtained. A total of 13706 olive trees were analyzed through serological and molecular techniques to verify the possible occurrence of the bacterium. Results: The cultivars "Nociara," "Cima di Melfi," and "Cellina di Nardò" showed the highest occurrence of decline symptoms. Tree age appears to be related to the incidence of decline symptoms. Olive trees growing in well-managed soils showed fewer symptoms than trees cultivated in farms where such agronomic techniques are not regularly performed. $X$. fastidiosa was detected in 2078 samples taken from symptomatic trees and 1653 samples obtained from asymptomatic trees. In 3300 samples taken from symptomatic trees, the bacterium was not detected.

Conclusions: Implementation and utilization of reliable in situ detection techniques could increase the number of sampled trees in each plot, thus allowing a more extensive and robust assessment of $X$. fastidiosa-infected plants in areas where the pathogen inoculums are still low.
\end{abstract}

\section{Keywords}

biocontainment, inspection, pathogen, biorisk management, infectious agent

\section{Introduction}

Xylella fastidiosa is a Gram-negative, slow-growing, xylemlimited bacterium that spreads to cultivated crops and wild plants through the feeding activities of insect vectors. It is considered among the most dangerous phytopathogens and is capable of killing many woody and herbaceous crops. Until recently, $X$. fastidiosa was restricted to the American continents, and consequently, the European Plant Protection Organization (EPPO) originally placed it in the A1 list of quarantine bacteria not present in Europe. However, starting in October 2013, many occurrences of this pathogen were reported for some European countries (ie, Italy, France, Spain, Germany, Switzerland, Portugal) and Iran.

$X$. fastidiosa includes some subspecies showing distinct molecular and pathogenic features. In the United States, $X$. fastidiosa subsp pauca, the causal agent of "citrus variegated chlorosis" in South America, is a regulated biological agent, and it is included in the Agricultural Bioterrorism Protection
Act. In Italy, $X$. fastidiosa subsp pauca is associated with the "olive quick decline syndrome" (OQDS), a severe disease widely occurring in Salento (Apulia region, southern Italy). The main symptoms include leaf, twig, and branch dieback followed by collapse of the crown and plant death. Most likely, the pathogen was introduced in Apulia through ornamental coffee plants originally grown in Central America and imported to Italy for commercial trade. ${ }^{1,2}$

\footnotetext{
' Council for Agricultural Research and the Analysis of Agricultural Economics (CREA), Research Centre for Olive, Fruit Trees and Citrus, Caserta, Italy

${ }^{2}$ Secretary Task force for Xylella fastidiosa, Regione Puglia, Bari, Italy

Corresponding Author:

Marco Scortichini, Council for Agricultural Research and the Analysis of Agricultural Economics (CREA), Research Centre for Olive, Fruit Trees and Citrus, Via Torrino 3, I-8I I I0, Caserta, Italy.

Email: marco.scortichini@crea.gov.it
} 
Due to its quarantine status and according to EPPO phytosanitary legislation, measures to avoid its further spread in the region were adopted soon after the pathogen discovery in the Apulia region. Among these, there was the Implementing Decision EU 2016/764 published on May 12, 2016, that delineated the so-called containment and buffer areas bordering the northern limit of the infected area. The latter is the area where the initial outbreaks of the disease were observed and where the infection has widely spread. In this area, due to the occurrence of the vector(s) and the very high and uniform density of olive orchards, the eradication of the pathogen has not been feasible. ${ }^{3}$ According to the European quarantine legislation, within the 20 $\mathrm{km}$-wide containment area, each olive tree found to be infected upon the performing of techniques developed to specifically detect $X$. fastidiosa must be uprooted. Within the $10 \mathrm{~km}$-wide buffer area, more severe rules are applied, and within a radius of $100 \mathrm{~m}$ that starts from the infected tree, all olive trees must be uprooted. The monitoring surveys of these areas are performed by inspectors of the Apulia region, who follow ad hoc rules for sampling.

The collection of field data related to OQDS and $X$. fastidiosa is also particularly important to assess some epidemiological aspects of the disease. Indeed, despite a relevant number of studies that have been performed to elucidate some features linked to the bacterium such as its taxonomy, origin, host range, vectors, and detection, the epidemiological aspects of OQDS and $X$. fastidiosa subsp pauca in Apulia are still largely unknown. For a more comprehensive understanding of olive tree decline, it is also important to analyze the information obtained from the areas where the infection is at an initial stage or absent and the symptoms of the decline are not widespread or very severe. In addition, no specific investigation on a large area has been performed aiming at ascertaining the occurrence of decline symptoms among the many olive cultivars currently grown in Apulia or verifying whether the positive or negative detection of $X$. fastidiosa is correlated with the presence of the symptoms.

To this aim, we analyzed and discuss the official data regarding 220279 olive trees obtained by monitoring the containment and buffer areas of Taranto and Brindisi provinces carried out between September 2017 and March 2018 by inspectors of the Agenzia Regionale per le attività Irrigue e Forestali (ARIF) of the Apulia Region. These surveys followed the Implementing Decision EU 2016/764 published on May 12, 2016, and the Ministerial Decree (December 7, 2016) of the Italian Ministry of Agriculture, Food and Forestry, "Misure di emergenza per la prevenzione, il controllo e l'eradicazione di Xylella fastidiosa Wells et al. nel territorio della Repubblica italiana." Previously, such an area was not intensively assessed for the presence of OQDS symptoms and the occurrence of the bacterium.

\section{Materials and Methods}

\section{Recording of Field Data and Sampling Procedures}

Between September 2017 and March 2018, the ARIF inspectors surveyed olive orchards and surrounding areas included within both the $20 \mathrm{~km}$-wide containment area and the $10 \mathrm{~km}$-wide buffer area of Brindisi and Taranto provinces, as delineated by the aforementioned Ministerial Decree. The 2 areas of approximately 190000 ha in total were divided into subareas of 250 ha, and each subarea was in turn subdivided into plots of 1 ha. Each plot was monitored to reveal the possible occurrence of olive trees showing symptoms of OQDS (ie, leaf, twig, and branch wilting or crown collapse). Before starting with the sampling, based on the direct survey or information obtained by the owner of the orchard, a notification form was compiled to reveal some basic features such as name of the cultivar, age of trees, soil management, occurrence of "olive knot," possibly caused by Pseudomonas savastanoi pv savastanoi, and "olive leprosy," possibly caused by Colletotrichum spp. Concerning $P$. savastanoi pv savastanoi, the typical "knot" symptoms on twigs and branches were scored, whereas for Colletotrichum spp, the symptoms were scored on the drupes. In the case of trees showing decline symptoms within a single plot, samples were taken from the tree showing the most extensive symptoms and from the 4 trees surrounding it. In the case of asymptomatic trees, the samples in the plot were taken at random from 1 single tree. For pathogen detection, 8 single leaf samples were taken from each selected tree according to the cardinal directions and at 2 different heights. To avoid involuntary spread of insect vector(s), each sample was checked for absence of any insect. Leaf samples were labeled, georeferenced, and placed into plastic bags. Two bags per each sample were used. Refrigerated containers were used to store the samples. A thorough check of the car to avoid the transportation of insects was performed before leaving the plot. Car windows were closed during the monitoring surveys. In the laboratory, samples were stored in refrigerated chambers maintained at $4^{\circ} \mathrm{C}$ $\pm 2^{\circ} \mathrm{C}$. Mature leaves taken from woody twigs were used for detection. To ascertain the occurrence of $X$. fastidiosa, an ELISA test and subsequently, quantitative real-time PCR assay for confirmation were performed. The official procedures established by the EPPO for $X$. fastidiosa detection were followed. After the analyses' completion, both the remaining plant parts and plastic bags and tubes were sterilized using autoclave.

\section{Results}

\section{Occurrence of Dieback Symptoms Among the Olive Cultivars}

A total of 220279 olive trees were taken into account for checking decline symptoms and the possible occurrence of $X$. fastidiosa. In the surveys, olive trees not necessarily grown in specialized orchards were also monitored. The extensive monitoring allowed us to ascertain either the occurrence of a very diverse olive germplasm cultivated in the containment and buffer areas or the incidence of decline symptoms recorded for these cultivars. A total of 33 different olive cultivars are grown to different extents in the surveyed areas. The monitoring recorded the occurrence of putative OQDS symptoms on 17755 trees, $8.06 \%$ of the total trees assessed. The occurrence 
of decline symptoms on the major cultivars grown in the areas was as follows: "Nociara" (16.31\%), "Cima di Melfi" (13.08\%), "Cellina di Nardò" (10.92\%), "Leccino" (8.45\%), "Coratina" (7.96\%), "Ogliarola salentina" (7.65\%), "Ogliarola barese" (7.41\%), and "Frantoio" (6.95\%).

\section{Age of Trees, Soil Management, Olive Diseases, and Dieback Symptoms}

Tree age appears to be related to the incidence of decline symptoms since older trees (more than 100 years old) showed more decline symptoms $(10.85 \%)$ when compared to those of younger trees (less than 50 years old), which showed decline in $6.53 \%$ of trees. Soil management could also play a role in relation to the occurrence of tree decline. Olive trees growing in well-managed soils (regular harrowing and removal of weeds) showed less symptoms $(7.42 \%)$ than trees cultivated in farms where such agronomic techniques are not regularly performed (13.78\%). Symptoms possibly caused by P. savastanoi pv savastanoi (olive knot) were observed on 10180 trees, with 2351 of these trees also showing decline symptoms. The number of trees showing symptoms attributable to Colletotrichum spp (olive leprosy) was 3533, with 273 also showing decline. Symptoms attributable to some "disorder" of unknown origin (not OQDS) were found on 10360 trees.

\section{Detection of X. Fastidiosa in Olive Trees}

ELISA and quantitative PCR analyses were applied to detect $X$. fastidiosa in samples taken from the surveyed areas. A total of 13706 trees were analyzed, among which 8328 trees were asymptomatic and 5378 showed symptoms of decline to different extent. $X$. fastidiosa was detected in 2078 samples taken from symptomatic trees and 1653 samples obtained from asymptomatic trees. In 3300 samples taken from symptomatic trees, the pathogen was not detected $(61.3 \%$ of symptomatic trees).

\section{Discussion}

These surveys allowed us to obtain useful information on some epidemiological aspects related to symptoms that could be putatively associated with the OQDS in Apulia. Leaf scorch and twig and branch dieback are among the most common symptoms associated with both OQDS and $X$. fastidiosa subsp pauca observed in the olive trees of the infected area (Lecce province) and are believed to precede subsequent extensive crown collapse and plant death. ${ }^{4}$ Leaf scorch and twig and small branch diebacks were found on $8.06 \%$ of the 220279 olive trees monitored in those areas, and some cultivars largely grown in the surveyed areas apparently showed more symptoms than others. Indeed, the cultivars "Nociara," "Cima di Melfi," and "Cellina di Nardò" showed a higher dieback occurrence than that of other cultivars grown in the same area such as "Ogliarola salentina," "Leccino," "Coratina," "Ogliarola barese," and "Frantoio."
It should be said that such symptoms are not specific to a single disease and cannot be attributable with certainty to a specific pathogen and/or insect without performing proper isolations and pathogenicity tests. Apart from X. fastidiosa, among the phytopathogens frequently associated with olive dieback in the Apulia region. Phaeoacremonium spp spread either in southern $^{5}$ or northern ${ }^{6}$ Apulia as well as Neofusicoccum parvum and Pleurostomophora richardsiae, with the latter considered to be the primary cause of the decline in northern Apulia. ${ }^{7}$ In addition, either $P$. savastanoi pv savastanoi, the causal agent of olive knot or, to lesser extent, Colletotrichum spp, causal agents of olive leprosy, can cause diebacks in olive trees. These latter 2 phytopathogens were reported in many cases of the monitored olive trees showing or not showing leaf scorch or twig and branch diebacks. It should be noted that in the initial phase of their plant colonization, both pathogens can incite knot and leprosy symptoms without causing wilting. Aspecific diebacks in olive trees can also be caused by insects such as Zeuzera pyrina (leopard moth) and Phloeotribus scarabaeoides (olive bark beetle).

Therefore, simple visual assessment of dieback symptoms is not enough to conclude which is the causal agent of the disease. Within this context, it should be said that 3300 olive trees showing decline symptoms tested negative for the occurrence of $X$. fastidiosa upon performing the detection assay in the laboratories. In contrast, 1653 asymptomatic trees tested positive for the occurrence of the bacterium, thus confirming the sensitivity of the current detection techniques. It should be said that in the infected area (Lecce province), where $X$. fastidiosa has been present for many years and has had the possibility to spread over a very large portion of the territory, there is a higher occurrence of the pathogen in trees showing OQDS symptoms.

To note that in the infected area, for olive trees older than 70 years, from the appearance of visual symptoms (leaf, twig, and small branch dieback) and the complete collapse of the plant caused by $X$. fastidiosa subsp pauca could occur over a period of approximately 2 to 4 years. ${ }^{8}$ From an epidemiological point of view of a plant disease, this is a long period, and during this time, other phytopathogens can cocolonize the trees weakened by the bacterium, thus potentially contributing to the final collapse. Ad hoc studies taking into account adult trees and subsequential coinfections performed with different olive pathogens during different periods of the year would seem useful to elucidate this facet of OQDS.

Reliable detection of this bacterium in areas not still heavily infected is fundamental for the identification of olive trees infected by $X$. fastidiosa. The detection efficiency could be augmented by increasing the number of trees sampled in each single plot. Currently, 5 trees per plot are sampled for further analyses in the laboratory to ascertain the occurrence of $X$. fastidiosa in trees showing decline symptoms. The utilization of portable detection tools allowing for in situ sampling and detection of the pathogen, if adequately validated on a large scale especially for specificity and sensitivity, could increase the number of trees monitored per plot. Both real- 
time loop-mediated isothermal amplification (real-time LAMP) ${ }^{9}$ and an electrochemical transduction method using a portable chip ${ }^{10}$ could potentially be utilized. In addition, in situ presymptomatic detection of the bacterium could potentially be performed by a portable instrument that analyzes mRNA of plant genes linked to OQDS (ie, biomarkers) using an infield qRT-PCR assay. ${ }^{11}$ In this case, the detection tool is strictly related to host response at the transcript level upon infection. If the field reliability of such techniques is confirmed by parallel analyses performed using real-time PCR, it would be possible to screen a larger number of trees per plot, thus obtaining more robust results. In addition, taking into account the long infection process characterizing $X$. fastidiosa subsp pauca in olive trees, another possibility to increase the reliability of detection is to perform an additional screening on "suspected" trees a few months after the first screening.

This extensive monitoring also allowed us to observe that tree age could be related to an increase in decline symptoms. A higher incidence of OQDS for older trees has also been observed in the Gallipoli area, where the decline was first observed. Tree age appears to be related to the differential production of primary and secondary compounds linked to plant metabolism, including the defense system, ${ }^{12}$ and differential mutation loads in meristematic tissues. ${ }^{13}$ However, specific studies concerning the $X$. fastidiosa-Olea europea pathosystem are currently lacking.

A neglect of soil management would also seem related to a higher occurrence of olive tree decline in both the containment and buffer areas. In the farms of these areas where soil harrowing is rarely carried out or not practiced at all, there was a higher occurrence of decline symptoms. It should be stressed that limiting the spread of $X$. fastidiosa subsp pauca within and between the olive orchards through the mechanical removal of weeds during the end of winter and early spring plays a fundamental role since it could drastically reduce the number of bacterium vectors in their juvenile phase. ${ }^{14}$ This agronomical practice is fundamental for limiting the vector populations.

\section{Acknowledgments}

The authors wish to thank Agenzia Regionale per le attività Irrigue e Forestali (ARIF) of Apulia Region for supplying the data.

\section{Ethical Approval Statement}

Not applicable

\section{Statement of Human and Animal Rights}

Not applicable

\section{Statement of Informed Consent}

Not applicable

\section{Declaration of Conflicting Interests}

The authors declared no potential conflicts of interest with respect to the research, authorship, and/or publication of this article.

\section{Funding}

The authors disclosed receipt of the following financial support for the research, authorship, and/or publication of this article: The study was financed by Regione Apulia through the Agreement: "Strategie di controllo integrato per il contenimento di Xylella fastidiosa in oliveti pugliesi ed analisi epidemiologiche del complesso del disseccamento rapido dell'olivo (CoDiRO)." [Integrated control strategies for control Xylella fastidiosa in Apulian olive orchards and epidemiological studies of olive quick decline syndrome (CoDiRO)]

\section{References}

1. Marcelletti S, Scortichini M. Xylella fastidiosa CoDiRO strain associated with the olive quick decline syndrome in southern Italy belongs to a clonal complex of the subspecies pauca that evolved in Central America. Microbiol. 2016;162(12):2087-2098.

2. Giampetruzzi A, Saponari M, Loconsole G, et al. Genome-wide analysis provides evidence on the genetic relatedness of the emergent Xylella fastidiosa genotype in Italy to isolates from Central America. Phytopathol. 2017;107(7):816-827.

3. Strona G, Carstens CJ, Beck P. Network analysis reveal why Xylella fastidiosa will persist in Europe. Sci Rep. 2017;7(1):71.

4. Martelli GP, Boscia D, Porcelli F, Saponari M. The olive quick decline syndrome in south-east Italy: a threatening phytosanitary emergence. Eur J Plant Pathol. 2016;44(2):235-243.

5. Nigro F, Boscia D, Anteli I, Ippolito A. Fungal species associated with a severe decline of olive in southern Italy. J Plant Pathol. 2013;95(3):668.

6. Carlucci A, Lops F, Cibelli F, Raimondo ML. Phaeoacremonium species associated with olive wilt and decline in southern Italy. Eur J Plant Pathol. 2015;141(4):717-729.

7. Carlucci A, Raimondo ML, Cibelli F, Phillips AJL, Lops F. Pleurostomophora richardsiae, Neofusicoccum parvum and Phaeoacremonium aleophilum associated with a decline of olives in southern Italy. Phytopath Medit. 2013;52(3):517-527.

8. EFSA (European Food Safety Authority) Panel PLH, Jeger M, Caffier D, Candresse T, et al. Scientific opinion on updated pest categorization of Xylella fastidiosa. EFSA J. 2018;6:5357.

9. Yaseen T, Drago S, Valentini F, et al. On-site detection of Xylella fastidiosa in host plants and in "spy insects" using the real-time loop-mediated isothermal amplification method. Phytopath Medit. 2015;54(3):488-496.

10. Chiriacò MS, Luvisi A, Primiceri E, Sabella E, De Bellis L, Maluccio G. Development of a-lab-on-a-chip method for rapid assay of Xylella fastidiosa subsp. pauca strain CoDiRO. Sci Rep . 2018;8(1):7376.

11. Martinelli F, Marchese A, Giovino A, et al. In-field and early detection of Xylella fastidiosa infections in olive using a portable instrument. Front Plant Sci. 2019;9:2007.

12. Turfan N, Alay M, Sariyildiz T. Effect of tree age on chemical compounds of ancient Anatolian black pine (Pinus nigra subsp. pallasiana) needles in Northwest Turkey. iForest 2018;11:406-410.

13. Tobias PA, Guest DI. Tree immunity: growing old without antibodies. Trends Plant Sci. 2014;19(6):367-370.

14. Cornara D, Bosco D, Fereres A. Philaenus spumarius: when an old acquaintance becomes a new threat to European agriculture. J Pest Sci. 2018;91(3):957-972. 